\title{
A CRÍTICA DE POPPER À ORGANIZAÇÃO SOCIAL IDEALIZADA POR PLATÃO
}

\section{POPPER'S CRITICISM TO THE SOCIAL ORGANIZATION IDEALIZED BY PLATO}

\section{RESUMO}

O presente trabalho objetiva analisar as características da sociedade idealizada por Platão em sua obra "A República". Adota-se como ponto de partida as críticas dirigidas à obra em consideração por Popper, que apontou Platão como um dos inimigos das sociedades abertas ou democráticas. A obra de Popper intitulada "a sociedade aberta e os seus inimigos" foi utilizada como marco teórico da pesquisa, realizada pelo método comparativo. Como problema de pesquisa, foi questionado se o modelo ideal de organização social esboçado por Platão em sua obra "A República" fornece (ou não) respaldo ao totalitarismo, tal como denunciou Popper. A hipótese inicial foi de que as críticas de Popper são pertinentes e acertadas.

Palavras-chave: Sociedades abertas. Idealismo platônico. Totalitarismo.

\section{ABSTRACT}

The present paper aims to analyze the characteristics of the society idealized by Plato in his book "The Republic". The criticisms directed at the book under consideration by Popper are taken as a starting point, who pointed out Plato as one of the enemies of open or democratic societies. Popper's book entitled "the open society and its enemies" was used as a theoretical framework for the research, carried out by the comparative method. As a research problem, it was questioned whether the ideal model of social organization outlined by Plato in his book "The Republic" provides (or not) support for totalitarianism, as denounced by Popper. The initial hypothesis was that Popper's criticisms are relevant and correct.

Keywords: Open societies. Platonic idealism. Totalitarianism.

\section{INTRODUÇÃO}




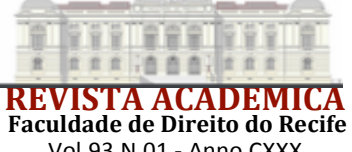

Voldade de Direito do Recife

Vol.93 N.01 - Anno CXXX

Platão é considerado um dos mais importantes filósofos que já existiu. Seus ensinamentos vêm sendo utilizados ao longo do tempo como argumento de autoridade em questões que transitam desde a política até a religião. Valores morais como o bem e a justiça são identificados como marcos indissociáveis de suas obras. Por isso, quando críticas são dirigidas à sua doutrina política associando-a a movimentos de consequências nefastas como o totalitarismo, impõe-se um aprofundamento nas bases fáticas e argumentativas delas.

O presente trabalho tem como ponto de partida as críticas de Popper ao modelo de sociedade e Estado idealizados por Platão, considerado por Popper inimigo da democracia e fornecedor de respaldo teórico a regimes totalitários. De acordo com ele, Platão buscou, por meio do desenho de uma sociedade e Estado ideais, defender privilégios de classe e interesses pessoais, colocando-se como alguém provido das qualidades necessárias para exercer o governo, sendo distinto dos seus contemporâneos.

O idealismo platônico, segundo as críticas que lhe foram dirigidas por Popper, em especial naquilo que se refere à organização política do Estado, tinha como foco criar um ambiente de consenso em torno da elevação do seu nome como o único capaz de resguardar asociedade da decadência. Sua finalidade seria desconstruir as bases da democracia ateniense, provendo o retorno para uma cultura com características tribais, semelhante ao que se verificava em Esparta, tida por ele como cidade culturalmente superior a Atenas, por cultivar os valores e o modelo organizacional que Platão considerava adequados.

Frente a esse cenário, como problema de pesquisa, questionamos se o modelo de sociedade esboçado por Platão em sua obra "A República" ampara as sociedades abertas ou democráticas.

Com o objetivo de confrontar as características da sociedade idealizada por Platão com as manifestações modernas dademocracia, partimos da hipótese de que aquele modelo idealizado é incompatível com as sociedades abertas ou democráticas.

A crítica da sociedade idealizada por Platão que empreendemos adotou Popper como marco teórico e foi realizada segundo o método comparativo, por do meio do qual as características do modeloplatônico foram extraídas e confrontadas com aquelas apresentadas pelas sociedades abertas ou democráticas.

$\mathrm{O}$ trabalho se encontra dividido em três capítulos. No primeiro, sintetizamos a obra "A República" de Platão, a fim de permitir uma visão conjunta das ideias que ele defendeu, bem como pontuamos as características do modelo socialque idealizou. No segundo, apresentamos a crítica de Popper ao modelo de sociedade e de governo idealizado por Platão. Já no terceiro, a partir da comparação das características da sociedade idealizada por Platão com a forma como o totalitarismo se estruturou no século XX, sustentamos que as críticas de Popper ao modelo social platônico foram acertadas.

\section{A REPÚBLICA: SÍNTESE DA OBRA E CARACTERIZAÇÃO DA SOCIEDADE IDEALIZADA POR PLATÃO} "livros".

A obra de Platão conhecida como "A República", encontra-se dividida em dez partes ou

O primeiro Livro, que inicia o diálogo, traz como cenário o regresso de Sócrates de uma procissão religiosa. Ele já se encontrava de saída da cidade, quando Adimantoordena a um escravo que o alcance. Ao retornar, Sócrates encontra Céfalo, o dono da casa, que inicia a conversa propondo uma reflexão sobre o exame de consciência que se faz na velhice, ao se vislumbrar a proximidade da morte. A discussão no Primeiro Livro concentra-se na busca de uma definição de justiça, sem que se alcance êxito em tal propósito. 


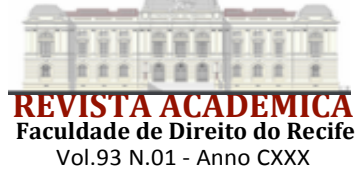

No Livro II, a controvérsiasobrea definição de justiça prossegue. Um ponto de destaque no livro é o mito do anel de Giges que, segundo a narrativa, deixava o seu possuidor invisível. Giges, um humilde pastor da Lídia, de posse dos poderes de invisibilidade que o anel lhe conferiu, tornou-se um monstro em decorrência da absoluta perspectiva de impunidade da qual passou a gozar em decorrência dos seus novos poderes. Nesta parte da obra, inicia-se também a discussão teórica a respeito da cidade perfeita, introduzida com a intenção de avaliar o conceito de justiça e injustiça no relacionamento entre os habitantes da cidade.

O Livro III começa com a discussão em tornodos parâmetros a serem seguidos na educação da classe dos guardiães. Um ponto importante nesta parte da obra é o mito relacionado à composição dos habitantes da cidade. De acordo com ele, os guardiães possuem ouro em sua composição; os soldados e auxiliares, prata; enquanto os lavradores e demais artífices são compostos por ferro e bronze.

No Livro IV, defende-se a imobilidade da estrutura social na cidade perfeita com base nos talentos que cada um dos habitantes possui. De acordo com esse pensamento, cada indivíduo deve ser conduzido para a classe cujos talentos se amoldem aos encargos dela.

A diferenciação entre os sexos, fundada nas tarefas para a qual cada habitante da cidade se encontra mais habilitado, é discutida no Livro V. A ideia de que as mulheres e os filhos devem ser compartilhados por todos os habitantes da cidade é defendida sob o argumento de que isso impediria a rivalidade entre os indivíduos que, por não conhecerem quais, de fato, seriam os seus filhos biológicos, teriam mais ânimo para se empenharem em favor do bem-estar da coletividade.

Nos Livros VI e VII é travada discussão a respeito da preparação do filósofo para assumir o governo da cidade. O ponto de maior destaque do Livro VII é a alegoria da caverna, de acordo com a qual os homens estariam atados em uma caverna escura, na entrada da qual haveria uma fogueira, que lhes possibilitaria, apenas, enxergar as sombras do que se passava no exterior. O filósofo seria o único indivíduo que havia tido a oportunidade de sair da caverna e contemplar a realidade externa. Logo, por ser dotado do conhecimento que obteve do mundo superior, ele deve assumir o encargo de orientar e conduzir os homens que ficaram presos no mundo inferior (a caverna).

As formas de governo da cidade são objeto de consideração nos Livros VIII e IX. Platão indica como formas possíveis de governo a timocracia, a aristocracia, a oligarquia, a democracia e a tirania. A timocracia, sendo um governo baseado na honra, seria a mais perfeita de todas. Já a tirania, por ser fundada na violência, é considerada a pior forma de se governar a cidade, segundo Platão.

O Livro X, considerado o epílogo da obra, distancia-se do núcleo daquilo que fora discutido nas demais partes. Nele, discorre-se sobre a arte poética, sendo os poetas considerados imitadores da forma real, o que leva Platão a criticá-los por isso. Segundo ele, a poesia desperta nos homens instintos irracionais, razão pela qual ela somente pode ser admitida na cidade ideal, caso se amolde às regras previamente estabelecidas.

Nos dez livros do diálogo "A República", a propósito de encontrar a definição de justiça, Platão (592b) $)^{2}$ apresenta o seu modelo de sociedade e Estado ideal, embora reconheça que ele não existe em lugar nenhum, sendo, portanto, um arquétipo por meio do qual osexistentes devem ser comparados, a fim de se identificar o quanto eles se aproximam da sociedade e do Estado ${ }^{3}$ ideal.

Na visão platônica, o modelo idealizado representa a perfeição. À medida que há distanciamento entre o real e o ideal, pode-se dimensionar o quanto aquilo que existe se encontra corrompido. Portanto, as característicasda sociedade e do Estado apresentadas por Platão na obra

\footnotetext{
${ }^{2}$ A tradução utilizada neste artigo foi a realizada por Maria Helena da Rocha Pereira, publicada em sua quinta edição pela Fundação Calouste Gulbenkian, cuja referência completa se encontra ao final do texto.

${ }^{3}$ Embora Platão não tenha utilizado o termo "Estado", uma vez que se trata de um conceito político moderno, utilizamos o termo como sinônimo de governo da cidade idealizada por Platão.
} 
que ora se discute devem ser entendidas como um modelo que precisa ser perseguido para se aproximar da perfeição.

$\mathrm{O}$ ideal em Platão não possui a sua existência vinculada à vontade dos homens. $\mathrm{O}$ modelo idealizado posta-se acima do real e representa o parâmetro de julgamento pelo qual aquilo que existe é avaliado, segundo o método comparativo. Opõe-se, segundo Strauss (2008, p. 196-197) ao convencionalismo, de acordo com o qual as regras de julgamento ou de direito são produzidas a partir de convenções criadas pelos homens.

Os modelos de Platão se encontram acima da realidade, sendo inatingíveis. São parâmetros de julgamento para fins de se avaliar o quanto a coisa analisada se encontra próxima da perfeição.

De acordo com Rogue (2011, p. 67) a realidade dos homens é considerada de ordem inferior na obra de Platão, o que coloca o modelo idealizado no âmbito inalcançável, do qual se pode, quando muito, aproximar-se. Com isso em mente, passa-se a elencar as características do modelo ideal de sociedade e Estado, tomado como sinônimo de governo na "República" de Platão.

A sociedade idealizada por Platão é estática, a mobilidade social somente ocorre quando algum indivíduo surge numa classe com talentos incompatíveis com ela, o que justificaria a sua transferência para aquela na qual as suas habilidades são demandadas. O individualismo é rejeitado. Todas as necessidades individuais somente são admissíveis quando compatíveis com o interesse maior da coletividade.

A natalidade é controladapelo governo (372c), pois não se pode admitir que o indivíduotenha filhos acima da sua capacidade de sustentá-los, valendo-se os genitores, para isso, do "receio da penúria ou da guerra". Mesmo esse controle de natalidade no Estado ideal não representa uma decisão individual, pelo menos na classe governante, uma vez que entre eles, as mulheres e os filhos devem ser compartilhados, de forma que eles não sejam capazes de identificar o pai ou mãe. Ausente a posse privada de mulheres e filhos, pretende-se evitar a discórdia entre os guardiães $(460 \mathrm{~d}-462 \mathrm{~d})$.

A preocupação maior de Platão na construção do seu modelo de sociedade idealizada centra-se na figura da classe dirigente, por ele chamada de guardiães. Ao sintetizar as características do guardião perfeito, Platão sustenta que ele deve ser "filósofo, fogoso, rápido e forte" (376c).

Embora tenha vislumbrado ser possível a mobilidade social, mediante a avaliação das habilidades do indivíduo, percebe-se que isso é difícil de ser concretizado, pois, de acordo com Platão, cada classe possui uma composição física diferente, de acordo com a posição social que ocupa. Assim, os guardiães possuem ouro em sua composição, os soldados e auxiliares prata, enquanto os lavradores e demais artífices são compostos por ferro e bronze (415a).

Como a estrutura corporal é distinta segundo a classe que o indivíduo ocupa, a mobilidade social resta prejudicada, uma vez que no próprio corpo do indivíduo estão presentes os elementos físicos que justificam a sua integração a uma determinada classe social. É como dividir a ocupação dos espaços sociais considerando, por exemplo, a cor da pele. Aquele cuja cor constituir o elemento de inserção numa determinada classe jamais poderá almejar a sua transferência para outra, uma vez que não se pode modificar os traços do seu fenótipo fixados de acordo com a sua constituição genética.

Logo, pode-se dizer que não existe mobilidade no modelo de sociedade idealizado por Platão. Cada um ocupa espaço previamente determinado com base em seu nascimento, o que torna falácia a promessa de ascensão social presente no Livro IV (423c $-435 d)$. Além disso, a possibilidade de mistura de classes sociais, segundo Platão, produz guerra e ódio (547abc).

O saber, de propriedade do filósofo, éa base do governo ideal platônico. Na alegoria da caverna, todos os homens estão atados a grilhões, impossibilitados de contemplarem a realidade, que se mostra para eles apenas por meio de sombras produzidas mediante a iluminação da caverna pela fogueira que se localiza em sua entrada. Tendo conseguido se desvencilhar das 


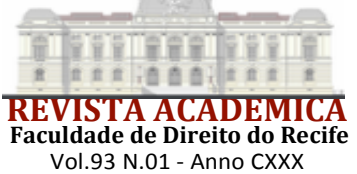

amarras, o filósofo logra êxito em sair da caverna e enxergar a realidade tal como ela de fato é. De posse desse conhecimento, ele assume a incumbência, ainda que contra a sua vontade, de retornar à caverna e guiar os demais homens que ficaram presos nela $(514 \mathrm{a}-520 \mathrm{~d})$.

O filósofo, segundo Platão, não ambiciona o poder. Ele é compelido para a posição de governante por ser dotado do saber necessário para conduzir os demais homens, uma vez que ele tem a visão do mundo superior, perfeito, enquanto os demais conseguem, no máximo, enxergar as sombras que são projetadas no interior da caverna.

A educação da classe dirigente é uma preocupação perene de Platão. A seleção daqueles que serão educados baseia-se na superioridade do caráter e na perfeição da forma física. A agudeza de espírito e a capacidade de aprender também necessitam ser consideradas (535abc).

A distinção na filosofia e na guerra são os requisitos primordiais, segundo Platão, para o exercício do governo (543abc).O compromisso com a verdade no trato dos governantes para com os governados não é fundamental na sociedade idealizada por Platão. Ele chega a defender que os governantes podem lançar mão da mentira frequente e de "dolos" no exercício de suas atribuições, desde que isso seja feito em benefício dos governados (459b).

No tocante ao formato de governo, Platão faz referência à timocracia, à aristocracia, à oligarquia, à democracia e à tirania, sendo a primeira a forma de governo mais perfeita e a última a pior delas (544c-545e). Para ele, as formas puras de governo ou constituição são a monarquia e a aristocracia (445d).

A honra constitui a baliza primordial da timocracia e da aristocracia. Na oligarquia, a riqueza credencia o indivíduo a participar do governo. A democracia, por sua vez, centra-se na liberdade e a tirania, na violência e no medo.

Platão não guarda grande apreço pela democracia e a coloca acima, apenas, da tirania. Ao descrever o seu surgimento, ele destaca que a democracia surge a partir de um processo de degeneração da oligarquia, centrado no conflito social, no qual os pobres vencem os ricos oligarcas e, após matarem uns e expulsarem outros, partilham o poder de forma igualitária com os que restam na cidade, dividindo entre si os governos e as magistraturas, sendo esses cargos, na maior partedas vezes, selecionados por meio de sorteio $(556 \mathrm{a}-557 \mathrm{c})$. Além disso, ele compara o surgimento da democracia a um jovem oligarca sem instrução, que decide viver de acordo com os impulsos dos seus desejos, uma vida livre e desordenada (559a-561e).

Quando a democracia se degenera, ela enseja o surgimento da tirania. Segundo Platão, nesse processo, o indivíduo se diz defensor do povo, conquista os seus corações, esmaga os opositores e se torna um tirano $(562 \mathrm{a}-566 \mathrm{e})$.

A partir das características traçadas por Platão, pode-se dizer que a sociedade ideal é coletivista, estática e seu governoé monárquico ou aristocrático, fundado no conhecimento e na habilidade de guerrear.

\section{A CRÍtica de POPPER AO MODELO IDEAL PLATÔNICO DE SOCIEDADE E GOVERNO}

Platão, ao longo do tempo, vem sendo visto como defensor de uma filosofia moral na qual o bem é ideal a ser perseguido, sendo considerado o filósofo mais próximo da tradição bíblica, preocupada, assim como ele, com a ideia de purificação (STRAUSS, 2008, p. 234). Popper (1987) apresenta visão diversa a respeito de Platão.

O conceito de tribalismo, considerado como a "[...] ênfase na suprema importância da tribo, sem a qual o indivíduo nada é em absoluto", inicia as considerações de Popper a respeito da organização social idealizada por Platão. Numa aristocracia tribal, cada indivíduo conhece e aceita a sua posição na escala social (POPPER, 1987, p. 23 e 26).

Popper (1987, p. 49 e 50) considera que a base metafísica ou especulativa da "teoria da mudança social” de Platão é o mundo das Formas ou Ideias imutáveis, "[...] de que é fruto o 
mundo das coisas mutáveis no tempo e no espaço". Como consequência, a perfeição e o bem constituem o ponto de partida, de sorte que toda mudança representa um movimento de afastamento dessa perfeição, a gerar formas corrompidas e imperfeitas. À medida que o distanciamento do ponto inicial avança, mais corrompido se torna o resultado, ou seja, a realidade produzida. Como decorrência disso, o repouso é divino, enquanto a mudança é má.

A política, em Platão, teria passado por quatro momentos distintos de degeneração. São eles a timarquia ou timocracia, no qual os nobres governam alicerçados na honra; a oligarquia, que tem como base o governo das famílias ricas; a democracia vista como um regime de liberdade e ausência de leis e a tirania, no qual a violência e o arbítrio imperam (POPPER, 1987, p. 53-54).

A divisão da casta governante em duas classes, ou seja, a dos guardiães e a dos auxiliares e a ausência de subdivisão semelhante na classe dos trabalhadores representa, segundo Popper, que o olhar de Platão se centralizou apenas na classe dirigente, o que o teria levado a defender o infanticídio com fins eugênicos em nome da pureza racial dos guardiães (POPPER, 1987, p. 61 e 65-66).

Popper (1987, p. 93-96) argumenta que Platão foi um defensor da "teoria orgânica do Estado", de acordo com a qual o Estado é considerado um organismo cujas partes convivem de maneira interdependente. Nesse modelo, cada indivíduo nada representa se estiver dissociado das funções que deve assumir na sociedade, o que legitimaria a sua eliminação quando não estiver encaixado no espaço que lhe fora reservadona coletividade.

De acordo com Popper (1987, p. 100-102) o programa político de Platão respalda o totalitarismo, na medida em que se opõe àmudança e defende o retorno às origens. A defesa dos privilégios de classe é considerada algo justo na visão de Platão, enquanto o individualismo é por ele combatido. Ele opunha o coletivismo ao egoísmo, procurando, o quanto possível, ignorar o individualismo, que se confronta com o sistema de castas que ele defendia em sua cidade idealizada. No âmbito político, o indivíduo é visto por Platão como a personificação do mal. A ele somente importa o coletivo e a justiça é vista como a saúde, unidade e estabilidade desse coletivo (POPPER, 1987, p. 105-121).

A "teoria da liderança" em Platão fundamenta-se no governo dos sábios, o que se opunha, inclusive, à visão de Sócrates, que acreditava na possibilidade de qualquer um ser educado e atingir a sabedoria (POPPER, 1987, p. 143 - 149).

Popper (1987, p.156-159) adverte que o mito dos metais utilizados na composição dos seres humanos (ouro, prata, ferro e cobre) expõe o prenúncio do racismo radical fundamentado em Platão. A isso se agrega a defesa da utilização das mentiras e propagandas como forma de enganar o povo, o que teria acabado por orientar as experiências totalitárias, em especial as vivenciadas ao longo do século XX.

O racismo em Platão se fez presente quando defendeu que, na classe dirigente, os nascimentos precisam ser submetidos ao rígido controle do Estado, como forma de originar uma raça de homens e mulheres "semelhantes aos deuses, se não divinos" (POPPER, 1987, p. 165).

De forma contundente, Popper (1987, p. 169-172) acusa Platão de ser, na verdade, o próprio "rei filósofo" e a República a sua reivindicação sobre o poder real. Platão seria, portanto, um ambicioso em relação ao poder, sendo a ideia do "[...] rei filósofoum monumento à pequenez humana". O desejo real de Platão seria convencer os seus contemporâneos de que ele era um ser dotado de atributos praticamente divinos, o que o credenciaria como o único capaz de salvar a cidade da decadência e da degeneração.

Ao sintetizar o programa político de Platão, Popper (1987, p. 153) destaca:

Em suma: o programa político de Platão foi muito mais institucional do que personalista: esperava ele deter a mudança política pelo controle institucional da sucessão na liderança. O controle devia ser educacional, baseado numa 


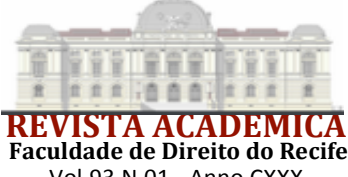

Vol.93 N.01 - Anno CXXX

concepção autoritária do ensino, na autoridade do perito letrado, do 'homem de comprovada probidade'.

O modelo de sociedade defendido por Platão é fechado, estático, avesso a mudanças, mágico, tribal e coletivista. Assemelha-se a um organismo, no qual cada membro possui uma função predeterminada (POPPER, 1987, p. 188).

De acordo com Popper, ao buscar defender o seu modelo de sociedade estática, Platão deturpou o pensamento do Sócrates histórico, que seria um crítico das instituições democráticas de Atenas, mas não um inimigo delas. Este Sócrates seria um humanista, democrata e defensor do individualismo. O platônico, em especial o que aparece na República, tinha como norte a defesa dos princípios do tribalismo, posicionando-se a favor de um modelo de sociedade fechada, voltado à defesa dos valores oligárquicos (POPPER, 1987, p. 205-213).

Popper (1987, p. 216-217) sustenta que a melhor lição que se pode extrair de Platão é o oposto daquilo que ele procurou ensinar. Isso porque, a detenção da mudança política e o retorno à sociedade fechada não constituem o remédio para os problemas do Estado. As incertezas da sociedade democrática, por ele chamada de aberta, representa o caminho capaz de assegurar a proteção da nossa humanidade, sendo a luz obtida na razão o instrumento capaz de guiar os seres humano.

\section{A SOCIEDADE IDEALIZADA POR PLATÃo E SUA PROXIMIDADE COM O TOTALITARISMO}

A obra de Platão vem sendo associada, ao longo do tempo, a valores como o bem e a pureza. Diante disso, as críticas tecidas por Karl Popper à sociedade e a sua forma de governo ideal que Platão esboçou em sua "República", causam certa inquietação aos que se deparam com elas. Mas, a avaliação da pertinência ou não das críticas demanda uma comparação entre as características do modelo idealizado por Platão e o formato assumido pelo totalitarismo que se manifestou no Ocidente na primeira metade do século XX.

O modelo ideal de Platão fundamenta-se numa sociedade fechada, com características tribais, voltada para os interesses do grupo, não abrindo espaço ao individualismo. Além disso, é desprovida de mobilidade de classes e rigidamente controlada, de forma autoritária, por seus guardiães. Possui um líder com habilidades especiais, denominado "rei filósofo" e busca a pureza racial e moral da classe dirigente.

Quando se compara o esboço do modelo ideal apresentado por Platão na "República", com os ideais que nortearam o totalitarismo, é possível identificar semelhanças.

A experiência do Estado totalitário no século XX demonstra a proximidade dele com a sociedade idealizada por Platão. O totalitarismo constituiu modelo de organização estatal com características peculiares, na qual o terror é, segundo Arendt (2012, p. 30, 402 e 405), o principal instrumento de atuação do Estado, gerador de grupos humanos sem proteção legal e desprovidos de interessados até mesmo para explorá-los, o que tornou a eliminação de seres humanos indesejáveis elemento cotidiano na operação da burocracia estatal.

A liberdade de escolha é um conceito inexistente no totalitarismo, pois, assim como na sociedade idealizada por Platão, os interesses maiores da coletividade é o que importa no processo de tomada de decisão. $\mathrm{O}$ indivíduo, quando incluído, representa apenas uma peça na engrenagem do Estado, encarado como organismo vivo, conduzido pelo líder, a quem se deve prestar obediência absoluta.

Arendt (2012, p. 439, 454 e 623) destaca que no totalitarismo as massas são organizadas pelo Estado sem vinculação a interesses específicos. Embora formem grandes aglomerações humanas, os indivíduos se sentem isolados e atomizados, incapazes de assumir qualquer 
protagonismo dissociado dos interesses do Estado. Os integrantes dessa sociedade fechada ${ }^{4}$ possuem o direito de existir, desde que resignados a desempenhar o papel que lhes cabe dentro dela. Os demais podem ser descartados, numa espécie de divisão social que cinde os seres humanos entre vítimas e carrascos.

A sociedade civil não existe no totalitarismo. Os indivíduos sentem-se isolados, atemorizados, incapazes de formarem grupos para a defesa de interesses privados. A sensação de ser a próxima vítima do aparelho repressor estatal provoca pânico generalizado entre os indivíduos, tornando-os impotentes para manifestar qualquer oposição ao Estado e, por consequência, àqueles que o controlam.

A traição, a desconfiança recíproca e o ódio em suas mais diversas faces são os sentimentos que norteiam o totalitarismo. Não existe qualquer respeito pela vida humana. Cada um pode ser aniquilado sem possibilidade de resistência, uma vez que o indivíduo atomizado não possui forças para se contrapor ao gigantismo do Estado.

O totalitarismo constitui a face extrema dos governos tirânicos. Trata-se de modelo estatal e de sociedade sem paralelo ao longo da história, uma vez que a busca por uma suposta purificação social promovida à base da incorporação da atividade de aniquilamento dos indesejáveis à burocracia estatal foi levada a cabo em sua plenitude. O totalitarismo enxerga a sociedade como um organismo, no qual cada indivíduo possui uma colocação previamente definida, sendo conduzida por um líder, a quem se deve prestar obediência absoluta. Os valores individuais nada representam e a busca da pureza racial, a fim de se alcançar uma sociedade provida de seres com características genéticas superiores é colocada como finalidade primordial ${ }^{5}$.

$\mathrm{Na}$ sociedade idealizada por Platão, assim como no totalitarismo,não existe poder soberano pertencente ao povo, exercido por meio de representantes eleitos ou mesmo diretamente. A liberdade e a igualdade formal, fundamentos democráticos, não possuem espaço no pensamento platônico. Acrescente-se a incompatibilidade da democracia com as hierarquias sociais, que possuem papel destacado na "República" de Platão.

Pode-se argumentar que a democracia moderna nasceu nos Estados Unidos da América e que o modelo democrático existente em Atenas na época de Platão e pelo qual ele não manifestava simpatia, difere do atual, razão pela qual isso não pode ser utilizado como critériode julgamento de sua obra. Mas, mesmo em face do desconhecimento da democracia representativa à época, não se pode desconsiderar que os fundamentos do Estado considerados primordiais por Platão são, em regra, incompatíveis com ela.

Por outro lado, o modelo idealizado por Platão fornece substrato para as sociedades fechadas, antidemocráticas, nas quais o indivíduo pouco ou nada representa, deferindo-se primazia para os interesses maiores de uma coletividade abstrata que, ao final, materializa-se nos interesses do líder e da classe social organizada em torno dele e que lhe confere sustentação. Logo, no Estado platônico, temos a existência de um líder dotado de características especiais, por ele chamado de "rei-filósofo" e que possui o encargo de conduzir os demais indivíduos, por ser dotado de uma visão de mundo diferenciada dos demais. No totalitarismo, temos também um líder a quem se deve prestar obediência absoluta e que, segundo a vertente totalitária, pode ser chamado de Duce, Führeretc.

Em Platão, a sociedade não possui mobilidade e o Estado prima pelo coletivismo, segundo uma visão organicista, na qual cada indivíduo possui funções previamente definidas de acordo com a classe social que ocupa. Do bom desempenho das funções de cada um depende o êxito do todo. O totalitarismo também defende um modelo de sociedade fechada, que enxerga cada indivíduo como uma peça agregada ao todo. Com isso, defende-se a possibilidade de eliminação daqueles que não se encaixam nesse organismo, sendo, por isso, desnecessários.

\footnotetext{
${ }^{4}$ A expressão "sociedade fechada" pertence a Popper, cuja obra também é discutida neste trabalho.

${ }^{5} \mathrm{~A}$ busca da pureza racial se manifestou, de forma mais intensa, no Nazismo alemão. O fascismo e o stalinismo não perseguiram, pelo menos como propósito maior, a pureza racial como uma finalidade do Estado.
} 
O Estado platônico é autoritário e exerce um rígido controle sobre a esfera privada, definindo o papel que cada um deve desempenhar, imiscuindo-se, inclusive, em questões como o número de filhos que cada indivíduo pode gerar. O Estado totalitário segue na mesma trilha. Nele, não há espaço para a liberdade individual, os indivíduos gerados com defeitos de ordem psíquica ou física devem ser eliminados, por não trazerem qualquer benefício para a sociedade. Além disso, todas as decisões tomadas precisam se amoldar aos interesses do Estado. Têm-se um cenário no qual os anseios individuais nada significam, sendo, não somente desestimulados, mas combatidos.

O modelo esboçado por Platão como sociedade e governo ideal não possui compromisso com a verdade. A propaganda pode ser utilizada como forma de desviar o foco dos governados de questões que não devam ser compartilhadas com todos os indivíduos, segundo os critérios de julgamento dos guardiães.

No totalitarismo, a propaganda estatal voltada a transmitir para a população conceitos tidos como importantes pelos dirigentes, o que, em regra, significava transmitir uma imagem distorcida da realidade, constituiu um dos mecanismos mais eficazes na construção do Estado totalitário. Dessa forma, assim como no Estado platônico, têm-se um rígido controle das informações que podem chegar ao conhecimento da população, bem como dos canais pelos quais elas podem ser transmitidas, haja vista que o cerceamento das liberdades de imprensa e de opinião são basilares no totalitarismo.

Arendt (2012, p. 474-499), demostra que a organização de um modelo de sociedade integralmente vinculado a uma ideologia, somente pode ser levado a cabo num regime totalitário. Para isso, a propaganda, por meio da qual se busca difundir uma visão de mundo integralmente associada aos interesses da classe dirigente, é fundamental para que o totalitarismo se estabeleça. Nesse contexto, pode-se lançar mão de falsas informações supostamente baseadas em pesquisas científicas sérias e até mesmo se admite a negação da realidade, tal como ocorreu durante o Stalinismo soviético quando difundiu, por exemplo, a falsa informação de que o metrô de Moscou era o único do mundo, o que era utilizado para sedimentar a suposta comprovação da superioridade tecnológica soviética e, por consequência, do comunismo na versão stalinista.

O foco de Platão em sua cidade ideal volta-se para a classe dirigente, cujo modelo de educação e até mesmo de reprodução é objeto de atenção especial. O Estado totalitário, por sua vez, preocupa-se primordialmente com os responsáveis por sua burocracia, com aqueles que possuem as características raciais ${ }^{6}$ tidas como superiores e com os eleitos pelo grande líder como especiais.O governo platônico fundamenta-se no conhecimento e na habilidade de guerrear. O totalitário considera a guerra primordial na evolução da sociedade e como a forma mais rápida de extirpar os seres considerados inferiores.

Verifica-se, pois, que as críticas de Popper ao Estado e à sociedade idealizados por Platão possuem solidez. Esse modelo de sociedade fechada, claramente inimigo de uma sociedade democrática, aberta e livre, pode ter servido de inspiração ao totalitarismo, embora esse fenômeno tenha sido mais amplo do que os anseios de retorno à sociedade tribal que inspirou Platão em sua "República".

É bem verdade que o totalitarismo possui características mais amplas do que as verificadas na República de Platão. Mas, aquelas ideias, quando agregadas ao evolucionismo, que sustentou a extirpação dos seres inferiores por aqueles melhor adaptados às condições de sobrevivência, bem como ao racismo que se encontrava bastante disseminado à época e encontrava respaldo em correntes científicas tidas como respeitáveis, acabaram por conduzir o mundo à experiência política mais devastadora de que se tem notícia na história.

\footnotetext{
${ }^{6}$ É importante deixa claro que o conceito de supremacia racial não é uma criação do Estado totalitário do século XX Arendt (2012, p. 233-266) demonstra que as raízes desse fenômeno são mais profundas e possuem, inclusive, fundamentação em correntes científicas tidas como respeitáveis na época. Logo, o racismo é um fenômeno antigo, embora nunca tenha sido usado antes como justificativapara eliminação em massa de seres humanos, tal como se verificou nos Estados totalitários.
} 


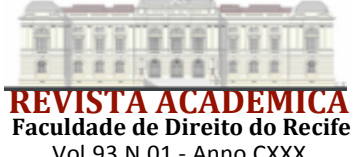

Vol.93 N.01 - Anno CXXX

A suposta busca pela definição de justiça, que serviu como justificativa teórica para o diálogo travado na "República" de Platão, prestou-se para que ele pudesse disseminar a sua ideia de que a organização da sociedade política não é um ato de liberdade dos cidadãos. Trata-se de intenção diversa, na qual, segundo Popper, ele buscou se credenciar como o único ser iluminado que existia à época e que poderia livrar a sociedade da decadência e do fracasso moral.

É problemáticona sociedade idealizada por Platão considerar que determinada parcela social se encontra em condições diferenciadas em relação às demais e, portanto, credencia-se para exercer o papel de governo. Veja-se que Platão defende que os indivíduos que se qualificam para serem guardiães devem receber instruções educacionais voltadas ao desempenho de suas finalidades. Isso contradiz o próprio argumento do autor de que esses seres são diferenciados. $\mathrm{Na}$ verdade, o que ele sustenta é que indivíduos considerados bem-nascidos, por descenderem das classes privilegiadas, precisam ser preparados para perpetuarem o domínio social que a sua classe já exerce, pois, se eles necessitam ser educados, é sinal de que, antes do processo educacional, seus dotes intelectuais não se diferenciariam, necessariamente, dos demais.

Platão acaba por referendar modelos sociais em que os privilégios de classe decorrem do nascimento, sendo falsa a sua defesa de que determinados indivíduos são considerados guardiães ou dirigentes por possuírem habilidades especiais para essas atribuições. A educação diferenciada que recebem em detrimento dos demais é que os tornam habilitados para continuar exercendo o papel de governo tradicionalmente atribuído à sua classe.

Essa visão de que existem seres humanos previamente habilitados para governar, enquanto aos outros cabe a obediência e a submissão fundamenta, ao longo do tempo, a formatação de sociedades divididas em classes ou castas que, no totalitarismo atingiu o ápice, ao gerar a formação de grupos aos quais se negou o próprio direito de existir, o que não havia sido cogitado em organizações sociais passadas.

Como já ressaltamos anteriormente, no idealismo de Platão o modelo esboçado representa a perfeição por meio da qual a realidade é julgada. Com isso, pode-se depreender que a sociedade perfeita em Platão é dividida em classes, provida de dominantes e dominados, na qual não é possível cogitar, sequer, de igualdade formal, tal como existente numa sociedade aberta ou democrática.

Por isso, embora consideremos temerário sustentar que Platão forneceu todo substrato teórico necessário ao totalitarismo, cremos não ser possível, por outro lado, ignorar que as suas ideias foram aproveitadas para legitimá-lo.Com isso, acreditamos que as críticas de Popper às ideias de Platão presentes em sua "República" são fundadas, pois o modelo de sociedade fechada que Platão idealizou aproxima-se daquilo que ficou conhecido como totalitarismo.

\section{CONCLUSÕES}

O modelo de sociedade que Platão defendeu em sua "República" prima pela imobilidade, pelo coletivismo, preocupa-se com a formação da classe dirigente, fundamenta-se no conhecimento e na habilidade de guerrear, seu governo é autoritário e controlador e sustenta-se na orientação de um líder com habilidades especiais, considerado como "rei-filosofo". Trata-se de uma sociedade fechada, que busca o retorno ao tribalismo.

Empreendemos essa pesquisa com a finalidade de identificar a organização política moderna com a qual esse modelo idealizado por Platão guarda proximidade, com o objetivo de analisar se são pertinentes as críticas direcionadas por Popper ao desenho teórico de sociedade ideal apresentado por Platão. Ao partir do pressuposto de que o totalitarismo fundamenta-se na fragmentação social e no isolamento dos indivíduos por meio do terror, pela presença de um líder supremo ao qual se deve prestar obediência absoluta, sendo a sociedade encarada segundo uma visão organicista, na qual cada indivíduo possui atribuições previamente definidas, justificando- 
se a exclusão e subsequente eliminação dos tidos por socialmente inúteis, chega-se à conclusão de que o modelo platônicorespalda o totalitarismo, embora não se possa dizer que guarde plena correspondência, uma vez que a eliminação em massa de seres humanos indesejáveis e o exercício do poder com base no terror são elementos que não se pode identificar na obra de Platão.

Logo, as críticas de Popper ao modelo social de Platão são pertinentes, pois ao defender o retorno à sociedade tribal fechada, Platão acabou por respaldar as manifestações de exclusão e divisão social fundadas no nascimento e na suposta superioridade de uma parcela dos indivíduos em relação aos demais, legitimando manifestações políticas autoritárias e fundadas na exclusão, dentre as quais o totalitarismo acaba sendo uma das possibilidades.

\section{REFERÊNCIAS}

ARENDT, Hannah. Origens do totalitarismo. Tradução Roberto Raposo. São Paulo: Companhia das Letras, 2012.

PLATÃO. A República. Introdução, tradução e notas Maria Helena da Rocha Pereira, 5 ed. Lisboa: Fundação CalousteGulbenkian, 1972 (?).

POPPER, Karl R.A sociedade aberta e seus inimigos. Tradução Milton Amado. Belo Horizonte: Itatiaia, 1987.

ROGUE, Christophe. Compreender Platão. Tradução Jaime A. Clasen. 6 ed. Petrópolis: Vozes, 2011.

STRAUSS, Leo. Estudios de filosofia política platónica. Buenos Aires: Amorrortu, 2008. 